\title{
OPEN Infant expectations of instant or delayed gratification
}

\author{
Yuyan Luo ${ }^{\bowtie}$ Duangporn Pattanakul
}

Choices between immediate gratification and long-term (but larger) gains are prevalent in human life, which is why the decision-making processes to delay gratification have been studied extensively throughout different developmental ages. Children's delay-of-gratification behaviors have been examined in the well-known "marshmallow test," in which 3- to 5-year-olds are given a marshmallow and told by an experimenter that they can eat it immediately or wait for an unspecified duration of time (which can be capped at $15 \mathrm{~min}$ ) until the experimenter returns so that they can receive another marshmallow. Children's wait time has been viewed as a good indicator of their later development. Here we show that a group of 22-month-old infants $(N=32)$ already held expectations about others' choices in a violation-of-expectation looking-time task modeled after the marshmallow test. The infants expected an agent to defer gratification based on a speaker's promise of the second marshmallow available in the future, but to eat the currently attainable marshmallow when the speaker made no such promise. Our findings indicate an early-emerging understanding of others' choices of delayed or instant gratification and shed new light on the development of delay-ofgratification behaviors.

People routinely make decisions on instant or deferred gratification, especially in situations concerning food intake. This is exactly the challenge faced by preschoolers in the delay-of-gratification paradigm ${ }^{1}$. Various factors sway children's decision of eating or waiting in the marshmallow test, for instance, their self-control skills-the ability to resist the temptation of instant reward (e.g., by distracting themselves) in order to obtain larger gains at a later point in time ${ }^{1,2}$, and children's trust in the experimenter's promise of the second marshmallow ${ }^{3-6}$. Importantly, children's wait time in the marshmallow test is considered a good predictor of their later development ${ }^{7-9}$ ( $\mathrm{se}^{10-12}$ for recent conversations on how social and environmental factors influence these longitudinal links). It remains unexplored, however, whether some early understanding about delay-of-gratification exists before individual differences can be observed in preschool years. That is, do infants hold general expectations about others' choices of delayed or instant gratification, before children are old enough to participate in the marshmallow test? The present study addressed this question.

There have been numerous reports of infants' understanding about the physical, psychological, and even moral domains of the world from the violation-of-expectation looking-time tasks ${ }^{13-15}$. The study rationale is that infants typically respond with heightened interest or prolonged looking to events that are inconsistent, as opposed to consistent, with their expectations. By measuring looking responses, these studies alleviate the requirements on the part of the young child to act on their knowledge (e.g., to answer an experimenter's questions) and thus yield findings that suggest the early emergence of cognitive competencies. The present study took a similar approach. Instead of asking children to wait patiently in the marshmallow test, we tested infants in a violationof-expectation looking-time task modeled after the marshmallow test to gauge their early understanding.

In the study, full-term, monolingual English-learning infants $(N=32)$ were randomly assigned to an experimental or a control condition, 17 male (age range: 18 months, 26 days to 24 months, 18 days; $M=21$ months, 25 days). We chose this age group based on previous infant studies with similar designs ${ }^{16,17}$. In the experimental condition, infants received six trials alternating between two types of events, wait or eat event, that involved two experimenters, a speaker and an agent (see Fig. 1). In both events, to start, the agent sat by a side window of an apparatus that resembled a stage, with an empty plate in front of her. Next, the speaker appeared by opening a window on the back of the stage. She looked at the agent, placed a marshmallow on the plate, and said to the agent, in infant-directed speech ${ }^{18}$, "Here is a marshmallow. You can eat it now, or if you don't eat it and wait for me to come back, I will give you another one." The speaker then exited the apparatus by closing the back window. The agent either waited while tapping her fingers on the apparatus (wait event) or ate the marshmallow and then tapped her fingers (eat event). The control condition was identical to the experimental condition except for what the speaker said to the agent. Instead of making a promise of an additional marshmallow, she simply said, "Here 

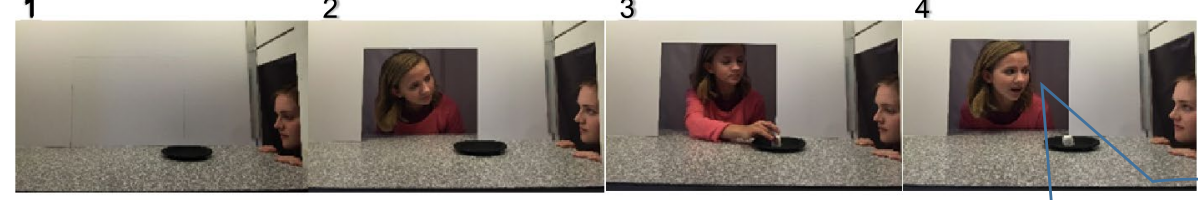

Eat Event $(1-4 \rightarrow 5 e-7 e)$

$5 e$ $6 e$ $7 e$

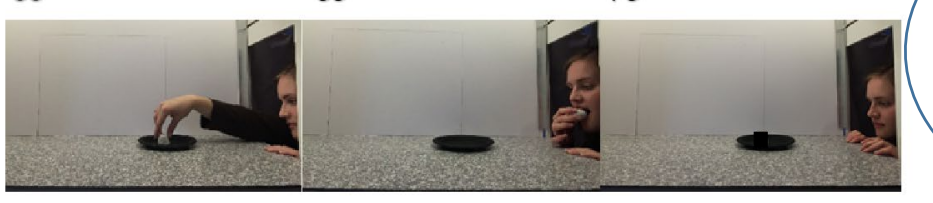
Experimental Condition: Here is a marshmallow. You can eat it now, or if you don't eat it and wait for me to come back, I will give you another one.

\section{Control Condition: Here is a} marshmallow. If you want, you can eat it now. Or, if you don't eat it, you can wait for me to come back.

Wait Event $(1-4 \rightarrow 5 w-7 w)$

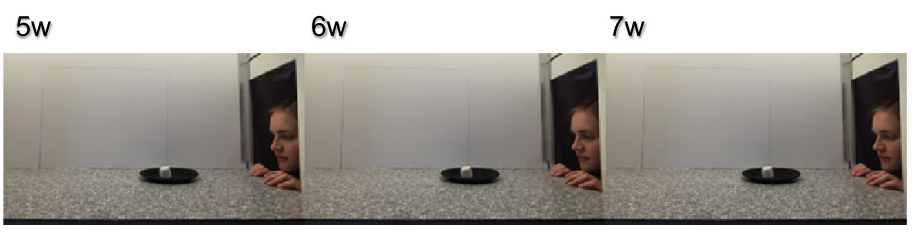

Figure 1. Schematic depiction of the two types of events shown to the infants in the experimental and control conditions. In each event, after watching the scene with an agent and an empty plate in front of her (1), the action sequence began in which a speaker appeared by opening a window, put a marshmallow on the plate, talked to the agent, and then left the apparatus by closing the window (2-4). The two conditions only differed in what the speaker said to the agent. In the eat event, the agent ate the marshmallow (5e-6e) and then tapped her fingers on the apparatus in the main trial (7e) until the trial ended. In the wait event, the agent never touched the marshmallow and only tapped her fingers $(5 w-6 w)$. She kept tapping her fingers in the main trial (7w) until the trial ended.

is a marshmallow. If you want, you can eat it now. Or, if you don't eat it, you can wait for me to come back." The sentences used in the two conditions were similar in structure as those used with infants at similar ages ${ }^{17}$.

Previous research has shown that toddlers are trusting of what other people say, even when it conflicts with their first-hand experiences ${ }^{19-21}$. This default to trust others' testimony is viewed as adaptive and serves cognitive and social functions early in life, e.g., to lay the foundations of language acquisition, or to establish connections with others ${ }^{22-24}$. Therefore, in the present study, infants would likely trust what the speaker said. In the experimental condition, if infants expected the agent to wait based on what the speaker had said to her, then they should respond with heightened interest when the agent ate the marshmallow immediately. We predicted that infants would look reliably longer at the eat event than at the wait event. In the control condition, by contrast, the speaker only listed to the agent the two choices, to eat or to wait, in the same order as in the experimental condition. There was no promise of a second marshmallow as the result of waiting. In this condition, infants should expect the agent to act on instant gratification and eat the marshmallow, as we humans have evolved to meet our basic needs for food ${ }^{25}$. We predicted that infants in the control condition would look reliably longer at the wait event than at the eat event. Thus, we hypothesized to obtain opposite patterns of results from the two conditions, although the two conditions were highly similar. Note that in the present study, the role of the agent was to carry out the actions of eating or waiting so that infants' looking responses to these actions could be measured. There was no requirement for infants to make any inferences about what the agent expected and/ or the interaction or relationship between the agent and the speaker.

\section{Results}

Infants received six trials alternating between the eat and the wait event, appropriate for their condition. Each trial consisted of a fixed-length action sequence (1-6 in Fig. 1) and a main trial (7 in Fig. 1). Infants' looking times in the main trial of the six trials were log-transformed to reduce positive skewness ${ }^{26}$. Analyses were performed on log looking times; raw looking times are provided below to facilitate communication.

Infants' log main-trial looking times were averaged and analyzed using a $2 \times 2$ repeated-measure analysis of variance (ANOVA) with condition (experimental or control) as a between-subjects factor and event (wait or eat) as a within-subject factor. The analysis yielded a significant Condition $\mathrm{x}$ Event interaction, $F(1,30)=15.83$, $p=0.0004, \eta_{p}^{2}=0.345$. No other effect was significant. Planned comparisons revealed that infants in the experimental condition looked reliably longer at the eat event $(M=24.74 \mathrm{~s}, S D=9.15)$ than at the wait event $(M=18.79 \mathrm{~s}$, $S D=10.45), F(1,30)=7.83, p=0.009$, Cohen's $d=0.657, t(15)=2.68$, Scaled Jeffreys-Zellner-Siow (JZS) Bayes Factor $=3.521^{27}$ in favor of the alternative hypothesis that infants would look differently at the two events over the null hypothesis, while those in the control condition looked reliably longer at the wait event $(M=30.67 \mathrm{~s}$, $S D=11.49)$ than at the eat event $(M=22.42 \mathrm{~s}, S D=10.64), F(1,30)=8.03, p=0.008$, Cohen's $d=0.705, t(15)=2.96$, 


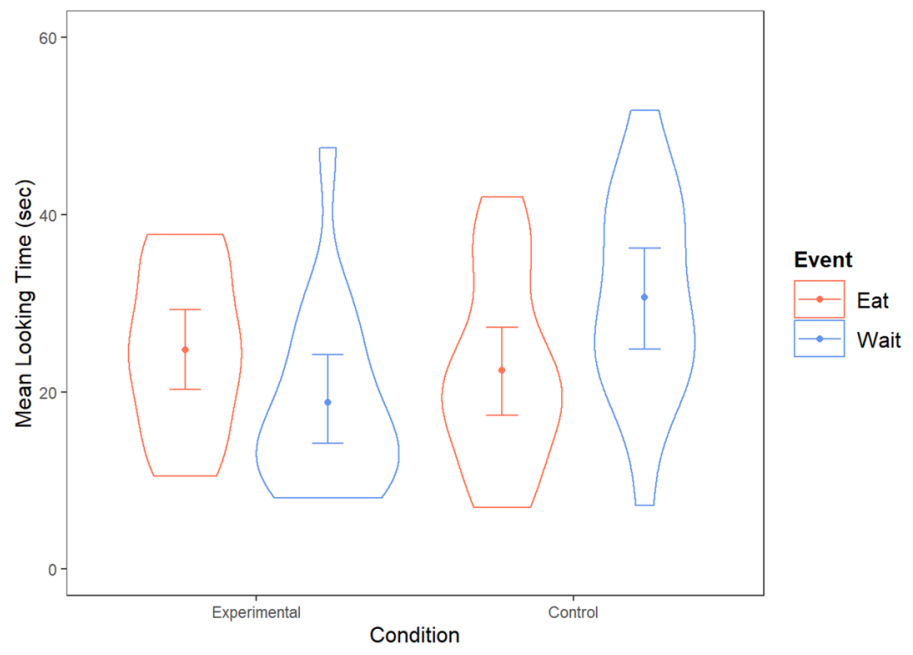

Figure 2. Violin plot of infants' mean looking times at the two types of events (eat or wait) in the experimental and control conditions. Dots represent condition means and error bars represent $95 \%$ confidence intervals. The kernel density plot on each side of the lines shows the probability of the data at different proportions.

\begin{tabular}{|c|c|c|}
\hline & Eat event & Wait event \\
\hline \multicolumn{3}{|c|}{ Experimental condition } \\
\hline First pair & $28.23(13.88)^{\star}$ & $18.39(13.45)$ \\
\hline Second pair & $25.31(17.91)$ & $23.31(16.54)$ \\
\hline Third pair & $20.01(15.35)$ & $13.97(8.16)$ \\
\hline \multicolumn{3}{|c|}{ Control condition } \\
\hline First pair & $30.19(23.20)$ & $47.86(27.95)^{\star}$ \\
\hline Second pair & $24.90(20.37)$ & $23.97(13.99)$ \\
\hline Third pair & $12.15(6.30)$ & $22.08(22.75)$ \\
\hline
\end{tabular}

Table 1. Mean looking times (in seconds) and standard deviations (in parentheses) at the two types of events in the first, second, and third pair of trials. ${ }^{\star}$ Greater than the other event, two-tailed $p<.05$.

Scaled JZS Bayes Factor $=5.593$ in favor of the alternative hypothesis (see Fig. 2). Nonparametric Wilcoxon signed-ranks tests confirmed these results (Experimental condition: $z=2.17$, two-tailed $p=0.03$; Control condition: $z=2.53$, two-tailed $p=0.011$ ).

In addition, we ran three analyses of covariance (ANCOVA) to examine the effect of infants' age, comprehensive or productive vocabulary size (as measured by the MacArthur Communicative Development Inventories (MCDIs) filled out by parents ${ }^{28}$ ), on the main results. With age (in days) as the covariate, the results replicated those of the ANOVA: the Condition x Event interaction was significant, $F(1,29)=11.78, p=0.0018$. Planned comparisons confirmed that infants in the experimental condition looked reliably longer at the eat than at the wait event, $F(1,29)=6.44, p=0.017$, whereas those in the control condition did the reverse, $F(1,29)=6.64$, $p=0.015$. These results still held when infants' comprehensive or productive vocabulary size was each included as the covariate (comprehensive vocabulary size: Condition $\mathrm{x}$ Event interaction: $F(1,29)=15.13, p=0.0005$; differences in the experimental condition: $F(1,29)=7.52, p=0.010$; differences in the control condition: $F(1,29)=7.74$, $p=0.009$; productive vocabulary size: Condition $\mathrm{x}$ Event interaction: $F(1,29)=15.28, p=0.0005$; differences in the experimental condition: $F(1,29)=7.54, p=0.010$; differences in the control condition: $F(1,29)=7.75, p=0.009)$.

Additional analyses. The results above were obtained with infants' log looking times averaged across three pairs of trials. To further examine infants' responses throughout the experiment, we first ran an ANOVA with condition as a between-subjects factor and event and trial pair (first, second, or third) as within-subject factors, although some infants did not contribute data to all three pairs (see Methods). While the Condition $\mathrm{x}$ Event interaction remained significant $(F(1,134)=9.75, p=0.002)$, there was no significant interaction of Condition $\mathrm{x}$ Event $\mathrm{x}$ Trial pair $(F(2,134)=2.20, p=0.115)$, suggesting that the effects in the two conditions did not change significantly across the three pairs of trials. Next, we performed paired $t$-tests on infants' log looking times at the two types of events in the first, second, and third pair of trials within each condition. In the experimental condition, infants looked longer at the eat event than at the wait event in all three pairs (see Table 1). The difference was significant in the first pair, $t(15)=3.60$, two-tailed $p=0.003$, but not in the second $(t(14)=0.35$, two-tailed $p>0.250)$ or the third pair $(t(12)=1.07$, two-tailed $p>0.250)$. In the control condition, infants looked longer at 
the wait than at the eat event in the first and third pairs (see Table 1). Similar to the experimental condition, the difference was only significant in the first pair, $t(15)=2.92$, two-tailed $p=0.011$ (second pair: $t(14)=0.06$, twotailed $p>0.250$; third pair: $t(12)=1.57$, two-tailed $p=0.143$ ). Therefore, in both conditions, while the respective effect was significant only in the first pair of trials, the effects did not vary by trial pair and the numerical differences in infants' looking time at the two events emerged even in the third pair of trials.

\section{Discussion}

These results suggest that while watching other people act, infants seem to hold general expectations of others' choices between delayed or instant gratification. In the violation-of-expectation task modeled after the marshmallow test ${ }^{1}$, when the speaker put a marshmallow in front of the agent and also promised her a second marshmallow if she waited in the experimental condition, infants seemed to have expected the agent to wait and responded with heightened interest when the agent ate the marshmallow. This expectation persisted across three pairs of trials, even though the speaker never fulfilled her promise throughout the experiment. Therefore, consistent with prior suggestions of an early default to trust what others say ${ }^{21}$, the infants appeared to believe in what the speaker said to the agent and made predictions about the agent's actions accordingly. In the control condition, in contrast, the speaker did not make a promise to the agent, infants hence seemed to expect the agent to eat the marshmallow and responded with heightened interest when she waited instead.

Therefore, even before their second birthday, infants expect others to wait and not eat an available marshmallow if given a promise of a second one. How do infants come to this appreciation? We speculate that infants' own experiences might contribute to the understanding, in addition to their trust in others' words. In the first two years of life, infants become increasingly adept at self-regulation, that is, to regulate and monitor their own behaviors and emotions in accord with external requirements and demands, for example, to comply with caregivers' requests and eventually internalize these requests ${ }^{29-31}$. In a situation in which an infant's mother told him/ her not to touch attractive toys that were easily accessible for eight minutes, for instance, the compliance rate gradually improved as infants developed, from $40 \%$ at 14 months to $78 \%$ at 22 months ${ }^{32}$. There are noticeable similarities between this situation and the present study, e.g., the requested inhibition of a powerful response of touching attractive toys or eating a marshmallow. It is thus plausible that while infants themselves are tasked with learning what is expected of them and complying with requests and even prohibitions from adults, they may also formulate a general expectation of compliance. In the present study, this expectation would have been satisfied by either one of the agent's choices, to eat, or not to eat but wait. In the experimental condition, however, infants' trust in the speaker's promise of a reward might have led to their predication that the agent should wait and not eat the marshmallow immediately. On the other hand, in the control condition, without this promise, the desire of consuming the marshmallow might have taken precedence and led to the prediction that the agent should eat.

The fact that the effects were found in the present study suggests that infants might have understood the gist of the speaker's speech, although we had no direct evidence for it. In our view, the important difference in the speaker's speech between the two conditions was the words "give," "and," and "another" (e.g., as in the speaker's promise "and ... I will give you another one" in the experimental condition). There is indirect support for infants' comprehension of these words. For example, compiled CDI data ${ }^{33}$ show that most 18 -month-old infants can understand "give" and by 22 months, about $20 \%$ of infants can even produce "and" and "another." A recent study ${ }^{34}$ further shows that 14 - to 18 -month-old Korean infants formed different expectations about an object's (i.e., a ball) location when they heard "the ball and the cup" versus "the ball is in the cup," pointing to early comprehension. However, in the present study, the speaker also used conditionals (the "if" sentences) in both conditions, which infants in the current age range rarely produce $e^{33,35,36}$. To our knowledge, no study has directly examined young children's understanding of conditionals. Nevertheless, recent work ${ }^{37-40}$ on infants' and toddlers' logical reasoning ( $\mathrm{A}$ or $\mathrm{B}$, if not $\mathrm{A}$, then $\mathrm{B}$ ) based on visual or linguistic information can speak to the possibility that rudimentary cognitive structures might be in place early in life to enable comprehension of conditionals. Additionally, conditionals exist in parental input even to their 12-month-olds, at least in structured caregiver-infant interactions ${ }^{41}$. This again seems consistent with our speculation that the effects found in the present study, which are unrelated to infants' vocabulary size, despite the variability of their age, may stem from these infants' socialization experiences.

The present study provides experimental evidence that infants hold expectations about instant or delayed gratification. It is still an open question how these early expectations translate to what infants do themselves (e.g., whether or how to embrace parental demands) and later preschoolers' responses in the delay-of-gratification paradigm (e.g., whether or how long to wait for an experimenter to get more treats). As mentioned earlier, children's self-control skills affect their delay-of-gratification behavior. Self-control is a broad construct that includes not only cognitive skills of executive functions (e.g., working memory, inhibitory control), but also self-regulation acquired through socialization ${ }^{42}$. While variances in cognitive skills, which are also shaped by experiences such as socialization ${ }^{43}$, can contribute to the individual differences found in the delay of gratification, the importance of the social and environmental influences on children's self-control has been highlighted by recent work ${ }^{44-48}$. For example, children may delay gratification because of cultural and/or parental expectations, or to conform to their in-group behavior ${ }^{45,47}$. Similarly, with regard to the development of self-regulation, researchers have also taken an integrative approach to examine a variety of social and environmental factors such as children's temperaments, parent-child relationships, and parenting practices, in addition to executive functioning skills ${ }^{30,49-51}$. In the present study, these factors were not considered. It is possible that the expectations of delayed gratification found in the present study are held by most if not all infants, despite their individual differences, presumably because of the general expectation of compliance and the default to trust others' words. It is also possible that there already might be differences in infant expectations because of variances in a wide range of factors such as caregivers' demands on infants, parent-infant interactions, and infants' experiences inside and 
outside their home environment. For instance, in resource-limited environment, delaying may not be adaptable, or individuals may be reluctant to trust others' promises because of a lack of reliability or predictability they have encountered $^{3,48}$. This might lead to infants holding expectations different than those found in the present sample (e.g., they might expect the agent to ignore the speaker's promise and eat the marshmallow in the experimental condition). Therefore, uncovering infant understanding before children can wait patiently themselves, e.g., in the marshmallow test, can help to elucidate the cognitive, social, and environmental influences on the dynamic development of delay-of-gratification behaviors.

\section{Methods}

Participants. Thirty-two healthy, full-term, monolingual English-learning infants, 17 male, participated (range: 18 months, 26 days to 24 months, 18 days; $M=21$ months, 25 days). Sixteen infants, 8 male, were randomly assigned to the experimental condition ( $M=21$ months, 14 days, $S D=36$ days), and the rest to the control condition $(M=22$ months, 7 days, $S D=35$ days). This sample size was determined by a power analysis using an effect size $f$ of 0.25 (Cohen's $d$ is approximately 0.5 ) and an alpha level of 0.05 for the $F$-test of a $2 \times 2$ between-within interaction design, which can achieve power of at least $0.75^{52}$. Another four infants were tested but excluded because of differences in test looking times more than 3 SDs from the mean of the condition $(n=2)$, being distracted $(n=1)$, or being exposed regularly $(\sim 90 \%)$ to a language other than English based on parental input $(n=1)$. Data collection for the present study was stopped after these 36 infants participated. Of the 36 infants, $86.11 \%$ were White, 5.56\% Asian, 5.56\% multiracial, and 2.78\% African American. The study was approved by the University of Missouri Institutional Review Board. The methods were carried out in accordance with the approved guidelines. Informed written consent was obtained from a parent or legal guardian of the participating infants. We also obtained informed written consent from the two experimenters shown in Fig. 1 of the study participation and publication of their images in an online open-access journal.

Apparatus. The apparatus consisted of a wooden display box $(106 \mathrm{~cm}$ high $\times 104 \mathrm{~cm}$ wide $\times 61 \mathrm{~cm}$ deep) mounted $76 \mathrm{~cm}$ above the room floor. The infant sat on a parent's lap and faced an opening $(56 \mathrm{~cm}$ high $\times 102 \mathrm{~cm}$ wide) in the front of the apparatus. Between trials, a curtain consisting of a muslin-covered frame $(61 \mathrm{~cm}$ high $\times 104 \mathrm{~cm}$ wide) was lowered in front of the opening. The side walls of the apparatus were painted white, and the floor was covered with a foam board wrapped with grey granite patterned contact paper. A rectangular window $(31.5 \mathrm{~cm}$ high $\times 30.5 \mathrm{~cm}$ wide $)$ was created in the right-side wall. The agent, wearing a brown shirt, sat by this window during the experiment. The speaker, wearing a pink shirt, sat behind a rectangular window $(35.5 \mathrm{~cm}$ high $\times 44.5 \mathrm{~cm}$ wide) created in the mid-section of the back wall made of white foam board. A large white cloth curtain covered the area behind her.

A round paper plate, $17 \mathrm{~cm}$ in diameter, was painted black and used in the experiment. On the apparatus floor, the plate was $21.5 \mathrm{~cm}$ from the agent's window and $7 \mathrm{~cm}$ from the back wall. Kraft Jet-Puffed white marshmallows were used. Each cylindrical marshmallow measured approximately $2.5 \mathrm{~cm}$ in diameter and $3 \mathrm{~cm}$ high.

The apparatus was also equipped with two video cameras. One recorded the events being shown on the apparatus, while the other recorded the infant. The input from the two cameras could be monitored online and checked offline to ensure proper testing. A metronome that beat softly once per second was used to help the experimenters adhere to the scripts.

Procedure. To determine an infant's vocabulary, the parent(s) filled out the MacArthur Communicative Development Inventories (MCDIs) ${ }^{28}$ before the experiment began. MCDIs are widely used parental reports for assessing communicative skills in infants and toddlers. The Level II short form MCDIs (Form A, for 16- to 30-month-olds) with 100 words listed were used. Parents checked how many of them their infant could comprehend and/or produce.

During the experiment, the infant sat on the parent's lap in front of the apparatus. Parents were instructed to close their eyes during the trials and not interact with the infants. After being seated in front of the apparatus, infants were greeted by the two experimenters, the speaker and the agent, one at a time. The speaker was always a native speaker of English. The experimenters were blind to the hypotheses of the study and were also required to follow the scripts (see below) designed to ensure that the events were presented similarly to each infant. Two naïve observers monitored the infant's looking behavior by viewing the infant through peepholes in large clothcovered frames on either side of the apparatus. Each observer held a controller linked to a computer software ${ }^{53}$ and pressed the button when the infant looked at the event. Looking times recorded by the primary observer were used for data analyses. For 8 of the 32 infants, only the primary observer was present. Inter-observer agreement for the remaining 24 infants averaged $93 \%$ per trial per infant.

In the experimental condition, the infants received six trials alternating between the eat and the wait events. Each event consisted of a 38-s action sequence and a main trial; looking times were computed separately. To start, the infant looked at the scene with the agent and the empty plate in front of her for 2 cumulative seconds. Next, the action sequence began. The speaker opened the back window ( $5 \mathrm{~s})$. The agent and the speaker turned to look at each other $(2 \mathrm{~s})$. The speaker then put a marshmallow on the plate $(3 \mathrm{~s})$ and said to the agent, "Here is a marshmallow. You can eat it now, or if you don't eat it and wait for me to come back, I will give you another one." (13 s) The speaker exited the apparatus by closing the back window (5 s). Following this, the last 10-s segment of the action sequence differed between the two types of events. In the eat event, the agent grabbed the marshmallow and ate it $(10 \mathrm{~s})$. In the wait event, the agent tapped her fingers on the edge of the apparatus (10 s). In the main trial, the agent kept tapping her fingers, with the empty plate (eat event) or the plate with the marshmallow on it (wait event) in front of her. The main trial ended when infants looked away for 2 consecutive seconds after having looked for at least 5 cumulative seconds or looked for 90 cumulative seconds. The control 
condition was similar to the experimental condition except for what the speaker said to the agent after putting the marshmallow on the plate. Across the two conditions, 15 infants, 8 male, saw the eat event first, and the remainder saw the wait event first.

Infants were attentive during the 38-s action sequence of the trials (range: 30 to $38 \mathrm{~s}$; experimental condition: $M=37.45 \mathrm{~s}, S D=0.94$; control condition: $M=36.69 \mathrm{~s}, S D=2.01)$. Across the two conditions, 26 infants contributed data from all three pairs of trials. The remaining infants contributed data from the first pair $(n=2)$ or from the first two pairs of trials $(n=4)$ because of experimenter error, refusal to continue, observer difficulty, equipment malfunction, parental interference, or being distracted. For these infants, the last two or the last one pair of trials were treated as missing data.

The infants' comprehensive vocabularies, as assessed by MCDI, were similar between the two conditions (experimental condition: range $=23$ to 100 , median $=70$; control condition: range $=8$ to 99 , median $=64$ ). The infants' productive vocabularies, however, differed between the two conditions, perhaps due to the fact that the mean age of the infants in the control condition was 23 days older than that of the experimental condition (experimental condition: range $=5$ to 96 , median $=25$; control condition: range $=3$ to 70 , median $=34.5$ ). The Pearson Correlations tests nevertheless confirmed that these two measures of infant vocabulary size were positively correlated within each condition (experimental condition: $r(14)=0.709$, two-tailed $p=0.002$; control condition: $r(14)=0.758$, two-tailed $p=0.001$ ).

Preliminary analyses of the log mean looking time data revealed no significant interactions of condition and event with sex or order, all $F s(1,24)<3.70$, $p s>0.066$; the data were therefore collapsed across sex and order in the main analyses.

Received: 3 March 2020; Accepted: 22 October 2020

Published online: 05 November 2020

\section{References}

1. Mischel, W., Shoda, Y. \& Rodriguez, M. I. Delay of gratification in children. Science 244, 933-938 (1989).

2. Metcalfe, J. \& Mischel, W. A hot/cool-system analysis of delay of gratification: dynamics of willpower. Psychol. Rev. 106, 3-19 (1999).

3. Kidd, C., Palmeri, H. \& Aslin, R. N. Rational snacking: young children's decision-making on the marshmallow task is moderated by beliefs about environmental reliability. Cognition 126, 109-114 (2013).

4. Mahrer, A. R. The role of expectancy in delayed reinforcement. J. Exp. Psychol. 52, 101-106 (1956).

5. Michaelson, L. E. \& Munakata, Y. Trust matters: seeing how an adult treats another person influences preschoolers' willingness to delay gratification. Dev. Sci. 19, 1011-1010 (2016).

6. Mischel, W. \& Ebbesen, E. B. Attention in delay of gratification. J. Pers. Soc. Psychol. 16, 329-337 (1970).

7. Casey, B. J. et al. Behavioral and neural correlates of delay of gratification 40 years later. Proc. Natl. Acad. Sci. 108, 14998-15003 (2011).

8. Shoda, Y., Mischel, W. \& Peake, P. K. Predicting adolescent cognitive and self-regulatory competencies from preschool delay of gratification: Identifying diagnostic conditions. J. Pers. Soc. Psychol. 26, 978-986 (1990).

9. Eigsti, I. M. et al. Predicting cognitive control from preschool to late adolescence and young adulthood. Psychol. Sci. 17, 478-484 (2006).

10. Doebel, S., Michaelson, L. E. \& Munakata, Y. Good things come to those who wait: Delaying gratification likely does matter for later achievement (A Commentary on Watts, Duncan, \& Quan, 2018). Psychol. Sci. 31(1), 97-99 (2019).

11. Watts, T. W., Duncan, G. J. \& Quan, H. Revisiting the marshmallow test: a conceptual replication investigating links between early delay of gratification and later outcomes. Psychol. Sci. 29(7), 1159-1177 (2018).

12. Michaelson, L. E. \& Munakata, Y. Same data set, different conclusions: preschool delay of gratification predicts later behavioral outcomes in a preregistered study. Psychol. Sci. 31(2), 193-201 (2020).

13. Baillargeon, R., Li, J., Gertner, Y. \& Wu, D. How Do Infants Reason About Physical Events? In The Wiley-Blackwell Handbook of Childhood Cognitive Development 2nd edn (ed. Goswami, U.) 11-48 (Blackwell, Oxford, 2011).

14. Baillargeon, R. et al. Psychological and Sociomoral Reasoning in Infancy. In APA Handbook of Personality and Social Psychology Vol. 1 (eds Mikulincer, M. \& Shaver, P. R.) 79-150 (American Psychological Association, Washington, DC, 2015).

15. Spelke, E. S. \& Kinzler, K. D. Core knowledge. Dev. Sci. 10, 89-96 (2007).

16. Jin, K. S. \& Baillargeon, R. Infants possess an abstract expectation of ingroup support. Proc. Natl. Acad. Sci. 114, 8199-8204 (2017).

17. Sloane, S., Baillargeon, R. \& Premack, D. Do infants have a sense of fairness?. Psychol. Sci. 23, 196-204 (2012).

18. Fernald, A. \& McRoberts, G. Prosodic Bootstrapping: A Critical Analysis of the Argument and the Evidence. In Signal to Syntax: Bootstrapping from Speech to Grammar in Early Acquisition (eds Morgan, J. L. \& Demuth, K.) 365-388 (Psychology Press, London, 1996).

19. Corriveau, K. H., Kinzler, K. D. \& Harris, P. L. Accuracy trumps accent in children's endorsement of object labels. Dev. Psychol. 49, 470-479 (2013).

20. Jaswal, V. K. Believing what you're told: young children's trust in unexpected testimony about the physical world. Cogn. Psychol. 61, 248-272 (2010).

21. Jaswal, V. K., Croft, A. C., Setia, A. R. \& Cole, C. A. Young children have a specific, highly robust bias to trust testimony. Psychol. Sci. 21, 1541-1547 (2010).

22. Baier, A. C. Trust and antitrust. Ethics 96, 231-260 (1986).

23. Coady, C. A. J. Testimony: A Philosophical Study (Clarendon Press, Oxford, 1992).

24. Jaswal, V. K. \& Kondrad, R. L. Why children are not always epistemically vigilant: cognitive limits and social considerations. Child Dev. Perspect. 10, 240-244 (2016).

25. Santos, L. R. \& Rosati, A. G. The evolutionary roots of human decision making. Annu. Rev. Psychol. 66, 321-347 (2015).

26. Csibra, G., Hernik, M., Mascaro, O., Tatone, D. \& Lengyel, M. Statistical treatment of looking-time data. Dev. Psychol. 52(4), $521-536(2016)$.

27. Rouder, J. N., Speckman, P. L., Sun, D., Morey, R. D. \& Iverson, G. Bayesian $t$ tests for accepting and rejecting the null hypothesis. Psychon. Bull. Rev. 16(2), 225-237 (2009).

28. Fenson, L. et al. Short-form versions of the MacArthur communicative development inventories. Appl. Psycholinguist. 21, 95-116 (2000).

29. Kochanska, G., Murray, K. T. \& Harlan, E. T. Effortful control in early childhood: continuity and change, antecedents, and implications for social development. Dev. Psychol. 36, 220-232 (2000).

30. Kopp, C. B. Antecedents of self-regulation: a developmental perspective. Dev. Psychol. 18(2), 199-214 (1982). 
31. Kopp, C. B. Regulation of distress and negative emotions: A developmental view. Dev. Psychol. 25, 343-354 (1989).

32. Kochanska, G., Coy, K. C. \& Murray, K. T. The development of self-regulation in the first four years of life. Child Dev. 72, 1091-1111 (2001).

33. Frank, M. C., Mika, B., Daniel, Y. \& Marchman, V. A. Wordbank: An open repository for developmental vocabulary data. J. Child Lang. 44, 1-18 (2016).

34. Jin, K. S. et al. Fourteen-to eighteen-month-old infants use explicit linguistic information to update an agent's false belief. Front. Psychol. 10, 2508 (2019).

35. Bloom, L., Lahey, M., Hood, L., Lifer, K. \& Fiess, K. Complex sentences: acquisition of syntactic connectives and the meaning relations they encode. J. Child Lang. 7, 235-261 (1980).

36. Bowerman, M. First Steps in Acquiring Conditionals. In On Conditionals (eds Traugott, E. C. et al.) 285-307 (Cambridge University Press, Cambridge, 1986).

37. Austin, K., Theakston, A., Lieven, E. \& Tomasello, M. Young children's understanding of denial. Dev. Psychol. 50(8), 2061 (2014).

38. Cesana-Arlotti, N. et al. Precursors of logical reasoning in preverbal human infants. Science 359(6381), 1263-1266 (2018).

39. Feiman, R., Mody, S., Sanborn, S. \& Carey, S. What do you mean, no? Toddlers' comprehension of logical "no" and "not". Language Learning and Development 13(4), 430-450 (2017).

40. Grigoroglou, M., Chan, S. \& Ganea, P. A. Toddlers' understanding and use of verbal negation in inferential reasoning search tasks. J. Exp. Child Psychol. 183, 222-241 (2019).

41. Grimminger, A., Rohlfing, K. J., Carina, L. Ü. K. E., Liszkowski, U. \& Ritterfeld, U. Decontextualized talk in caregivers' input to 12-month-old children during structured interaction. J. Child Lang. 47(2), 418-434 (2020).

42. Moffitt, T. E. et al. A gradient of childhood self-control predicts health, wealth, and public safety. Proc. Natl. Acad. Sci. 108, 2693-2698 (2011).

43. Doebel, S. Rethinking executive function and its development. Perspect. Psychol. Sci. 15, 942-956 (2020).

44. Diamond, A. \& Lee, K. Interventions shown to aid executive function development in children 4 to 12 years old. Science 333 , 959-964 (2011).

45. Doebel, S. \& Munakata, Y. Group influences on engaging self-control: children delay gratification and value it more when their in-group delays and their out-group doesn't. Psychol. Sci. 29, 738-748 (2018).

46. Duckworth, A. L., Tsukayama, E. \& Kirby, T. A. Is it really self-control? Examining the predictive power of the delay of gratification task. Pers. Soc. Psychol. Bull. 39, 843-855 (2013).

47. Lamm, B. et al. Waiting for the second treat: developing culture-specific modes of self-regulation. Child Dev. 89, e261-e277 (2018).

48. Sturge-Apple, M. L. et al. Vagal tone and children's delay of gratification: differential sensitivity in resource-poor and resource-rich environments. Psychol. Sci. 27, 885-893 (2016).

49. Murray, K. T. \& Kochanska, G. Effortful control: factor structure and relation to externalizing and internalizing behaviors. J. Abnorm. Child Psychol. 30, 503-514 (2002).

50. Rothbart, M. K. \& Bates, J. E. Temperament. In Handbook of Child Psychology. Social, Emotional, and Personality Development 6th edn, Vol. 3 (eds Damon, W. et al.) 99-166 (Wiley, New York, NY, 2006).

51. Eisenberg, N., Duckworth, A. L., Spinrad, T. L. \& Valiente, C. Conscientiousness: origins in childhood?. Dev. Psychol. 50, 1331-1349 (2014).

52. Faul, F., Erdfelder, E., Lang, A. G. \& Buchner, A. G* Power 3: a flexible statistical power analysis program for the social, behavioral, and biomedical sciences. Behav. Res. Methods 39, 175-191 (2007).

53. Baillargeon, R. \& Barrett, J. Baby. An Experimental Software Program for Infant Looking Time Experiments. [Computer Software] (2005).

\section{Acknowledgments}

We thank Eryn Adams, You-jung Choi, Sabine Doebel, Patricia Ganea, Ashley Groh, Alice Guo, Lori Markson, Rose Scott, Maayan Stavans, Kristy vanMarle, and two anonymous reviewers for helpful suggestions, the University of Missouri Infant Cognition Laboratory for their help with data collection, and the parents and infants who participated in the research.

\section{Author contributions}

Y.L. developed the study concept and drafted the manuscript. D.P. analyzed the data. Both authors were involved in data collection and approved the final version of the manuscript for submission.

\section{Competing interests}

The authors declare no competing interests.

\section{Additional information}

Correspondence and requests for materials should be addressed to Y.L.

Reprints and permissions information is available at www.nature.com/reprints.

Publisher's note Springer Nature remains neutral with regard to jurisdictional claims in published maps and institutional affiliations.

(c) (1) Open Access This article is licensed under a Creative Commons Attribution 4.0 International (c) License, which permits use, sharing, adaptation, distribution and reproduction in any medium or format, as long as you give appropriate credit to the original author(s) and the source, provide a link to the Creative Commons licence, and indicate if changes were made. The images or other third party material in this article are included in the article's Creative Commons licence, unless indicated otherwise in a credit line to the material. If material is not included in the article's Creative Commons licence and your intended use is not permitted by statutory regulation or exceeds the permitted use, you will need to obtain permission directly from the copyright holder. To view a copy of this licence, visit http://creativecommons.org/licenses/by/4.0/.

(C) The Author(s) 2020 